\title{
Nuevos datos biográficos sobre Joaquín Mosquera y Figueroa localizados en documentos (1796-1806) del Archivo General de la Nación
}

\author{
Yolia Tortolero Cervantes \\ Comité Regional para América Latina y el Caribe \\ del Programa Memoria del Mundo, UNESCO \\ yoliatortolero@yahoo.com
}

\section{Resumen}

Joaquín Mosquera y Figueroa (1748 -1830), criollo originario de Popayán (Nueva Granada), Colombia, se formó como abogado en Santa Fe de Bogotá. Fue oidor de la Real Audiencia de Santa Fe de Bogotá en 1787; alcalde del crimen en la Real Audiencia de México (1795-1803), oidor de la Real Audiencia de México (1803-1805); regente visitador de la Real Audiencia de Caracas (1805-1809) y presidente de la Regencia del Reino España (1812-1813).

En este artículo se reúnen algunos apuntes biográficos sobre Mosquera $y$, en particular, se analiza su paso por la Nueva España, con base en documentos localizados en el Archivo General de la Nación (AGN).

Palabras clave: Joaquín Mosquera y Figueroa; reales audiencias de Santa Fe, Nueva España, Caracas

\section{Abstract}

Joaquín Mosquera y Figueroa (1748 -1830), "criollo", was born in Popayan (Nueva Granada), Colombia, and became a lawyer in Santa Fe de Bogotá. He worked for the Royal Audience of Santa Fe in 1787, and later for the Royal Audience of México (1795-1805). Then he assumed a temporary commission at the Royal Audience of Caracas (1805-1809) and after this period, moved to Spain where he became President of the Regency (1812-1813).

This article summarizes his biography and analyzes some records from the National Archives of México related to the life of Joaquín Mosquera during the period he worked in New Spain.

Keywords: Joaquín Mosquera y Figueroa; royal audiences of Santa $\mathrm{Fe}$, New Spain, Caracas 
Tortolero, Nuevos datos...

Este artículo fue escrito durante mi estancia posdoctoral (2014-2015) en apoyo al posgrado nacional, auspiciada por el CONACYT, en el programa de la Maestría en Historia (Estudios Históricos Interdisciplinarios) de la Universidad de Guanajuato. 


\section{Introducción}

La trayectoria política y jurídica de Joaquín Mosquera y Figueroa (Popayán, 20 de enero de 1748-Madrid, 25 de mayo de 1830), aporta evidencias sobre los mecanismos de ascenso profesional y las oportunidades de movilidad política que hubo en los virreinatos y posesiones españolas en América, especialmente para quienes fueron reconocidos por sus méritos en el desempeño de sus cargos como funcionarios, unidos a sus actitudes de lealtad a la monarquía y su cercana relación con los virreyes en turno.

Las circunstancias de Mosquera son dignas de atención porque cuando parecía consolidado en sus cargos en el virreinato de la Nueva Granada fue promovido para ir a la Ciudad de México (a la edad de 47 años), donde trabajó durante diez años en la Real Audiencia de la Nueva España, luego fue comisionado para ocupar un puesto, aparentemente temporal, como regente visitador de la Real Audiencia de Caracas, que se prolongaría durante cuatro años, del cual logró separarse bajo circunstancias "adversas", pero bien calculadas por él debido, precisamente, a su dominio del funcionamiento de la burocracia virreinal y al conocimiento del tiempo requerido para concluir los trámites. Es decir, en cuanto consiguió un nuevo nombramiento oficial para poder renunciar, de inmediato, gestionó las autorizaciones correspondientes para continuar su carrera jurídica y política en España, prácticamente hasta su muerte, a los 82 años.

La historiografía colombiana habla poco sobre Joaquín Mosquera y Figueroa, en comparación con otros miembros de su familia, como Joaquín Mariano de Mosquera y Figueroa y Arboleda, quien mantuvo una relación cercana con Simón Bolívar y fue presidente de la Gran Colombia en 1830, o bien, Tomás Cipriano de Mosquera y Arboleda, quien fuera presidente de Colombia en cuatro ocasiones, la primera de ellas en $1845 .^{1}$

${ }^{1}$ Para ampliar este tema se recomienda consultar en línea el catálogo de la Biblioteca Nacional de Colombia, que contiene una muestra importante de títulos sobre la familia Mosquera en www.bibliotecanacional.gov.co 
En la historiografia mexicana pareciera que la figura de Joaquín Mosquera y Figueroa ha sido prácticamente ignorada, pues se le consideró un funcionario más entre los que integraron la abultada burocracia del virreinato de la Nueva España. Sin embargo, el estudio de su desempeño profesional constituye un campo de análisis en construcción, sobre todo si se toma en cuenta la inmensa y variada cantidad de asuntos que resolvió durante diez años en materia de justicia dentro de la Real Audiencia de México. Bastaría pensar que se le conoció más por los temas que atendió con eficacia, que por su desempeño, aun cuando obtuvo prestigio por hacerlo muy bien. En este sentido, falta profundizar en su labor como jurista en la etapa crucial en la que llegó a México, antes del inicio de la Independencia.

En la historia venezolana, a diferencia de Colombia y México, Joaquín Mosquera y Figueroa ha sido objeto de diversos estudios, ${ }^{2}$ debido a que el cargo que ocupó como regente visitador en la Real Audiencia de Caracas desató - entre las élites locales y de gobiernomultitud de reacciones adversas, debidas a la función que desempeñó para descubrir la red de corrupción que existía en la institución y en el gobierno de la Capitanía General de Venezuela. ${ }^{3}$ En parte, la amplitud de sus facultades fue lo que le permitió investigar a todos los miembros de la Real Audiencia, incluyendo al personal subalterno y al regente, abrir averiguaciones orales y secretas de testigos y denunciantes, resguardar toda la documentación pertinente, levantar cargos a los magistrados para determinar el cumplimiento de sus deberes y el grado de participación en sobornos. ${ }^{4}$

${ }^{2}$ Algunos de ellos consultados en la Academia Nacional de la Historia de Venezuela, otros, en la biblioteca del Instituto de Investigaciones Históricas Bolivarium de la Universidad Simón Bolívar, en Caracas.

${ }^{3}$ López Bohorquez, La Real Audiencia de Caracas: razones de su creación, p. 43.

${ }^{4}$ López Bohorquez, La Real Audiencia de Caracas en la historiografia venezolana, pp. $570-571$. 
Teresa Albornoz, autora venezolana, fue una de las primeras académicas en realizar una exhaustiva investigación sobre el tema, en la que utilizó las fuentes localizadas en su país y en el Archivo de Indias en Sevilla. Su libro constituye un aporte sustantivo acerca de las redes de corrupción que hubo en Caracas cuando Joaquín Mosquera fungió como regente visitador; también, menciona datos sobre los cargos que desempeñó en México y los primeros años de su llegada a España. ${ }^{5}$

Quizá la investigación más reciente es la que actualmente lleva a cabo el español Carlos Arnulfo Rojas Salazar, quien publicó, en 2014, un artículo del protagonismo de Joaquín Mosquera y Figueroa en España entre 1809-1813, con base en fuentes inéditas que localizó en el Archivo General de la Nación de Colombia, así como en archivos españoles como el Archivo General de Palacio, el Archivo Histórico Nacional de España y el Archivo de Protocolos Notariales de Madrid. ${ }^{6}$ El estudio se centra en 1809 y 1812, de hecho, no se detiene mucho a hablar del momento en que Mosquera pasó por la Nueva España, pero reconstruye muy bien el tiempo en que radicó en España, en especial, dimensiona su gestión como funcionario público en sus distintos nombramientos, sobre todo, durante su actuación en la convocatoria a las Cortes de Cádiz y en la firma de la Constitución en 1812.

La complejidad de escribir una biografia integral sobre Joaquín Mosquera y Figueroa se debe a su larga vida y a su amplia trayectoria; estos factores - como se observa en la mayoría de fuentes bibliográficas

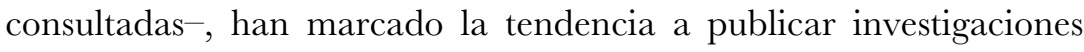
fragmentadas o concentradas sólo en alguna de sus etapas profesionales, y en alguno de los lugares donde se estableció.

Una de sus biografías más completas fue publicada en 1971 por Benjamín Bentura, quien cubre con detalle cada faceta de la vida personal y profesional de Mosquera. Sin embargo, omite citar

${ }^{5}$ Véase Albornoz de López, "La visita de Joaquín Mosquera y Figueroa a la Real Audiencia de Caracas (1804-1809): conflictos internos y corrupción en la administración de justicia".

${ }^{6}$ Rojas Salazar, "Un realista neogranadino: don Joaquín Mosquera y Figueroa", p. 127. 
con precisión sus fuentes bibliográficas y documentales - no del todo comprobables- las cuales se confunden con su lenguaje florido y estilo literario basado en algunos datos ficticios.

Por otra parte, la evidente dispersión de los archivos que se localizan en Popayán, Cartagena, Bogotá, México, Caracas y España, dificulta la reconstrucción completa y bien documentada sobre el personaje; por ejemplo, en el caso de los acervos colombianos resultaría indispensable incorporar el archivo de la familia Mosquera que se encuentra en la Universidad de Cauca en Popayán, el Archivo General de la Nación de Colombia y el Archivo Mosquera de la Biblioteca Luis Ángel Arango del Banco de la República, entre otros.

En México, existen acervos con valiosa información sobre la gestión de Joaquín Mosquera en la Real Audiencia de la Nueva España, en particular, las causas importantes que le correspondió abrir y cuyos expedientes generados en ese periodo están en el Archivo General de la Nación (AGN); entre ellos, el juicio sobre el levantamiento del grupo de criollos insurrectos, sucedido en 1799, conocido como la "Conspiración de los machetes", que aconteció durante el gobierno de Miguel José de Azanza, virrey de la Nueva España entre 1798 y 1800. Asimismo, en el Fondo Indiferente Virreinal del AGN han aparecido, en los pasados diez años, expedientes relevantes como la correspondencia que en 1806 Joaquín Mosquera envió desde Caracas al virrey Iturrigaray, documentos que se transcribieron en un artículo publicado en Legajos. Boletín del Archivo General de la Nación, en 2012.7

Un aspecto interesante de estudiar a Mosquera cuando dejó México para dirigirse a Venezuela es que viajó solo, sin su esposa e hijas, lo cual permite conocer datos de su vida privada que aparecen en algunos documentos oficiales, que envió durante los años que residió en Caracas. A su vez, habría que rastrear en qué lugar Joaquín

7 Tortolero Cervantes, Yolia, "Un expediente en el Indiferente Virreinal del AGN", pp. 159-198. 
Mosquera o sus herederos, dejaron sus papeles familiares, porque de acuerdo con los documentos revisados, cuando salió de Caracas hacia España, viajó con una parte importante de su archivo personal.

Por otra parte, existe documentación relevante en el Archivo General de la República Bolivariana de Venezuela y en la Academia Nacional de la Historia, que se complementa con los sendos expedientes de la Real Audiencia de Caracas del Archivo de Indias en Sevilla, que fueron utilizados por Teresa Albornoz, quien los incluyó en su publicación en un anexo que contiene las transcripciones de los documentos originales que consultó; de hecho, muchos de ellos no fueron empleados en el cuerpo de su análisis, por lo que constituyen materiales valiosos, poco estudiados, sobre la vida de Mosquera. ${ }^{8}$

El propósito del presente artículo es ofrecer una síntesis biográfica con información dispersa en distintas fuentes bibliográficas, articuladas con un conjunto de datos inéditos, puntuales, que localicé en diversos expedientes del AGN. Estos documentos se refieren a la vida de Joaquín Mosquera y Figueroa, específicamente, cuando radicó en la Nueva España.

\section{Primera etapa: de Popayán a México}

Carlos Arnulfo Rojas Salazar menciona en su artículo ${ }^{9}$ que Joaquín Mosquera y Figueroa nació en una de las familias "más ricas, tradicionales y aristocráticas del virreinato neogranadino", la cual, "junto con los Valencia, fueron los mayores propietarios de minas, haciendas y cuadrillas de esclavos en la Gobernación de Popayán, durante el siglo XVIII".

En un documento localizado en el AGN de México, se mencionan varios datos biográficos de interés, entre ellos, que fue:

${ }^{8}$ Albornoz de López, La visita de Joaquín Mosquera y Figueroa.

${ }^{9}$ Rojas Salazar, Un realista neogranadino, p. 127. 
hijo legítimo del capitán don Joseph de Mosquera y de doña María Teresa de Arboleda, personas de notoria nobleza, y descendientes de conquistadores y pobladores de aquellas provincias, habiendo obtenido en ellas los de sus familias empleos honoríficos de la República y otros del Real servicio. ${ }^{10}$

Joaquín Mosquera y Figueroa salió a los 19 años de Popayán, su ciudad natal, para estudiar en Santa fe de Bogotá. Primero:

fue Colegial en el mayor de nuestra Señora del Rosario de la Ciudad de Santa Fe, donde cursó con conocido aprovechamiento la Filosofía, Cánones y Leyes [...] logrando los grados correspondientes hasta el de Doctor en ambos Derechos por la Universidad de Santo Tomás de la expresada Ciudad de Santa Fe, y que por su inclinación a los estudios se le eligiese para regentar las Cátedras de Latinidad y Retórica de dicho Colegio, del cual fue varias veces Consiliario y dos años Vice-Rector. ${ }^{11}$

Después:

se mantuvo quatro años más leyendo las cátedras de vísperas de cánones y sexto de decretales, con notorio adelantamiento de los alumnos [...] y atendiendo el Muy Real Arzobispo que fue de Santa Fe don Fray Agustín Camacho a sus buenas circunstancias y literatura, le eligió el seis de septiembre de 1772 por Promotor Fiscal de su Curia Eclesiástica; y habiendo completado los años

${ }_{10}$ AGN, Fondo Indiferente Virreinal, volumen 120, expediente 18. Años 1795-1799. Documento "Relación de los méritos y servicios del Doctor Don Joachin de Mosquera y Figueroa, Oidor que fue de la Real Audiencia de Santa Fe y actual alcalde del Crímen de la ciudad de México".

${ }^{11}$ Ibid. 
de práctica correspondientes, se recibió de Abogado de la Real Audiencia de Santa Fe el veinte y uno de febrero de $1774 .^{12}$

Ese mismo año, el 5 de noviembre, el virrey del Nuevo Reino de Granada lo nombró teniente gobernador de la provincia de Popayán, con facultades para asesorar al gobernador en los asuntos militares. Más tarde:

por fallecimiento de Don Juan Antonio de Celaya, Gobernador de Popayán, se encargó de la conclusión del Puente Real de Cauca, presentando al Ayuntamiento las cuentas de su coste en 1778 [...]. ${ }^{13}$

Ese mismo año, a consulta del Consejo de Indias y resolución real, se le asignó el empleo de teniente gobernador y auditor de guerra de la plaza y provincia de Cartagena de Indias, "dando posesión del cargo el 7 de diciembre de 1778". ${ }^{14} \mathrm{El}$ entonces gobernador de Cartagena, don Juan Pimienta, el 12 de agosto de 1780, opinó que le constaba que el teniente de gobernador Mosquera "Se manejaba en el despacho de los muchos y graves negocios que de toda clase ocurrían, con el mayor acierto y prudencia, y una incesante aplicación, mostrando en la fácil expedición de ellos su mucha instrucción, y haciendo conocer su zelo en los del Público y Real Hacienda." Como resultado "dio un feliz movimiento al crecido número de causas criminales, que ocurrían de toda la Provincia, hasta lograr ver despejada la cárcel" $[\ldots] .^{15}$

\footnotetext{
${ }^{12} \mathrm{Ibid}$.

${ }^{13}$ Ibid.

${ }^{14}$ Ibid.

${ }^{15}$ Ibid.
} 
Finalmente, "el 3 de octubre de 1787 tomó posesión del cargo de Oidor de la Real Audiencia de Santa Fe, que estaba vacante por muerte de Don Joseph Zubiria". ${ }^{16}$

De los cargos anteriores, cuando fue teniente y auditor de guerra de Cartagena, Mosquera denunció un cuantioso fraude en la aduana de esa Provincia, ${ }^{17}$ lo cual marcó un precedente en su carrera y méritos políticos porque, a partir de entonces, se ganó la confianza de los virreyes de Nueva Granada y Nueva España, quienes le asignaron subsecuentes cargos que implicaban investigar actos de corrupción en otras instituciones del gobierno español en América.

Otra de sus facetas le valió para consolidarse como detector de infidentes, para proteger los intereses de la monarquía española, en especial a partir de que fue nombrado oidor de la Real Audiencia de Santa Fe de Bogotá en 1787, en cuyo periodo le correspondió hacer seguimiento al proceso contra Antonio Nariño en 1794, acusado por haber difundido el texto los "Derechos del hombre y del ciudadano". El juicio de Nariño trajo a Joaquín Mosquera y Figueroa complicaciones de orden político, entre otras razones porque generó diferencias de opinión entre la audiencia y el cabildo de Santa Fe de Bogotá. Esa coyuntura le llevó a ser promovido por sus méritos, para ocupar el cargo de alcalde del crimen en la Real Audiencia de México en marzo de 1795. Precisamente, en los documentos del AGN que hacen referencia al nombramiento que Mosquera recibió, ${ }^{18}$ se entiende que fue un ascenso, en virtud de los retos que enfrentó en una institución virreinal de mayor arraigo y complejidad, en la que

${ }^{16}$ Ibid.

${ }^{17}$ Rojas Salazar, "Un realista neogranadino", p. 217.

${ }^{18}$ En el AgN varios expedientes hacen referencia al título que recibió Mosquera como "Alcalde del Crimen de la Audiencia de México": AGN, Fondo Indiferente Virreinal, caja 5323, Sección Criminal, expediente 6, año 1796, 4 ff.; Fondo Indiferente Virreinal, caja 5372, Sección Criminal, año 1796, 4 ff. y Fondo Real Audiencia, volumen 39, expediente 7, año 1796, 5 ff. 
su buen desempeño le llevó a subir de rango hasta ocupar el cargo de oidor en $1803 .{ }^{19}$

\section{Su paso por Nueva España}

Joaquín Mosquera y Figueroa llegó a Nueva España con muy buenas referencias de su desempeño en la Real Audiencia de Santa Fe. En diciembre de 1795 el virrey de la Nueva Granada, José de Ezpeleta envió desde Santa Fe de Bogotá al virrey de la Nueva España, Marqués de Branciforte, una carta señalando las virtudes de Mosquera.

Tuve ocasión de conocer la integridad, la prudencia y tino que tiene en el expediente de los negocios el Oydor que era de esta Real Audiencia Don Joaquín de Mosquera y Figueroa, y habiéndole por tanto consultado en todo género de asuntos experimenté siempre en ellos el acierto de sus dictámenes, su imparcialidad y sus deseos del mejor servicio del Rey, por los quales abrazó el extraordinario trabajo que le causaron mis consultas, sin faltar al exacto desempeño de las obligaciones de su empleo en el Tribunal y considerando que por haver sido trasladado dicho Ministro a ese Reyno, convendrá se halle Vuestra Excelencia con noticias de sus circunstancias, no me he detenido en comunicarlas a Vuestra Excelencia por lo que pueda importar al servicio de Su Majestad y por la justa estimación que me ha merecido este sujeto, a quien no puedo dar otra prueba de ella, que la de su mérito y sus luces, persuadido a que la confirmará Vuestra Excelencia en cualquier caso que tenga a bien hacer uso de ellas. ${ }^{20}$

${ }^{19}$ Las fechas en que ocupó estos y otros nombramientos se detallan en el libro de Bentura, El hidalgo payanés, pp. 202-205.

${ }^{20}$ AGN, Fondo Indiferente virreinal, caja 6635, Real Audiencia, expediente 38, fecha: 1795, $3 \mathrm{ff}$. 
En respuesta a esta carta el virrey de Branciforte, en febrero de 1796, agradeció al virrey de la Nueva Granada la recomendación que hiciera sobre Mosquera. ${ }^{21}$ En otra misiva del marqués de Branciforte, firmada en Orizaba el 30 de agosto de 1797, el propio virrey resaltó las cualidades de Mosquera, con el fin de promoverlo y ascenderlo a oidor en los siguientes términos:

Don Joaquín de Mosquera y Figueroa fue promovido de Oydor de la Real Audiencia del Reino de Santa Fe a Alcalde del Crimen de la de México por los méritos y buenos servicios que contraxo en aquél empleo.

Convirtiera en celo y actividad con que sin fallar a la asistencia diaria en la referida Audiencia de Santa Fe desempeñó con acierto varias comisiones que confió el Virrey Don José de Ezpeleta a su literatura, entre ellos la delicada sobre rumores de inquietud y sedición ocurrida en dicho Reyno el año de 1794, el despacho de la Asesoría general y Auditoría de Guerra del mismo Virreynato por espacio de más de seis años, executando en horas extraordinarias de su descanso, sin que por este encargo hubiese solicitado gratificación ni ayuda de costa alguna, manifestando un desinterés con haver cedido a las partes todos los derechos que se devieran satisfacerle de honorarios, y finalmente que en la última guerra con los franceses fue el primero que acreditó su amor al soberano ofreciendo donativo gracioso para las vigencias de la corona antes que su Majestad se hubiese dignado mandar admitir estas generosas ofertas.

Son notoriamente importantes y públicos estos servicios contraídos por Mosquera en los años de que satisfecho Yo, y de su pureza, talento y literatura he puesto

${ }^{21}$ AGN, la carta está en el mismo expediente, citado con anterioridad, fechada el 15 de febrero de 1796. 
al cargo de este benemérito Ministro comisiones delicadas y de reserva, en cuyo desempeño ha dado nuevas pruebas de instrucción, desinterés y constante celo.

Por estas circunstancias se ha hecho digno de mi aprecio y concepto, juzgándolo acreedor a las gracias con que Nuestro Augusto Soberano premia y distingue a sus fieles servidores. Para que así se verifique suplico a Vuestra Excelencia se sirva instruir de todo a Su Majestad, inclinado su Real animo como lo ruego a Vuestra Excelencia eficazmente, a fin de que se digne conceder a Mosquera el regular ascenso de Oydor de la propia Audiencia de México respecto a que de ser promovido a otra fuera de este Reyno, se le originarían graves atrasos en el transporte de su crecida familia". ${ }^{22}$

De acuerdo con la biografia escrita en 1971 por Benjamín Bentura, Joaquín Mosquera y Figueroa vivió en Nueva España con su esposa María Josefa García de Toledo y sus hijas Dolores, Isabel y María Teresa "siendo que estas tres ingresaron en el convento de las Carmelitas Descalzas de la Ciudad de México para prepararse para ser monjas". ${ }^{23}$

Para ampliar la idea de sus actividades como alcalde del crimen (1795-1803) y oidor de la Real Audiencia de la Nueva España (18031805), en los que intervino como autoridad para resolver distintos casos, existen, por ejemplo, un informe que dirigió a la junta de policía sobre los disturbios en algunas calles de la Ciudad de México en $1797{ }^{24}$ la prisión de indios en Tlaxcaltepec y Temascaltepec en

${ }^{22}$ AGN, Fondo Instituciones Coloniales, Gobierno virreinal, Correspondencia de virreyes, vol. 188, 30 de agosto de 1797, 2 ff. (ff. 81-81v).

${ }^{23}$ Bentura, El hidalgo payanés, pp. 168-200.

${ }^{24}$ AGN, Fondo Indiferente Virreinal, caja 6182, Sección Policía y empedrados, expediente 24 . 
$1796,{ }^{25}$ o bien, la queja de la esposa de un panadero de la Ciudad de México quien denunció al alcalde de cuartel por obligar a su marido a trabajar encerrado, sin permitirle salir durante 26 días de la panadería ubicada en la calle "de los ciegos". ${ }^{26}$ Otro caso fechado en 1800 se refiere a los autos contra Manuel de la Cruz y Santiago de la Cruz, ambos indios Pames de las Misiones de San Luis de la Paz, asuntos que fueron del conocimiento del virrey Miguel Joseph de Azanza. ${ }^{27}$ Otro caso fue el relacionado con los avances en la construcción de caminos en Jalapa y las heladas que afectaron el maíz y la cebada en esa ciudad en $1804 .^{28}$ Por último, se encuentra una lista de expedientes que le asignaron en 1804 para atender cuestiones relativas a las Californias, particularmente, en torno a la muerte de marineros, sumarias y diligencias. ${ }^{29}$

En esa etapa de la vida de Mosquera, otros resultados por su desempeño como alcalde del crimen y oidor de la Real Audiencia, destacaron porque:

corrió con la Comisión de Vagos, de que formó más de 700 causas, por encargo del Virrey Marqués de Branciforte; dotó de tripulación a buques de la Habana; persiguió con la mayor actividad los juegos prohibidos; y con base en el Bando del Conde de Revillagigedo de 1792 dio a las Penas de Cámara (así llamadas las multas que se imponían

${ }^{25}$ AGN, Fondo Real Audiencia, Sección Indios, volumen 88, expediente 7, año 1796, ff. 47-55.

${ }^{26}$ AGN, Fondo Real Audiencia, Sección Judicial, volumen 56, expediente 9, años 1793-1820, 6 ff.

${ }^{27}$ AGN, Fondo Indiferente Virreinal, caja 3308, expediente 49, año 1800, 2 ff., documento: Oficio dirigido por Guillermo de Aguirre, José Mexia, Joaquín de Mosquera y Figueroa al Virrey Miguel José de Azanza, fechado el 12 de marzo de 1800.

${ }^{28}$ AGN, Fondo Indiferente Virreinal, caja 830, Sección Correspondencia de virreyes, expediente 8, año 1804.

${ }^{29}$ AGN, Fondo Indiferente Virreinal, caja 3436, Californias/Secretaría de Cámara del Virreinato, año 1804. 
a los funcionarios virreinales), un total de 9,550 pesos, sin que haya memoria que lo haya hecho otro ministro. ${ }^{30}$

También:

Se le encargó la Protectoría de la Casa de Recogidas de México, en ocasión de hallarse destruidas tres casas propias del Recogimiento, y a costa de arbitrios de mérito, consiguió el reparo de las dos.

[Por su parte], el Virrey Marqués de Branciforte lo nombró por Vocal de la Junta formada a consecuencia de Real Orden, para la substracción de la grave causa del homicidio perpetrado en la persona del Gobernador de Yucatán Don Lucas de Gálvez [...] y satisfecho el mismo Virrey de su acreditado talento, actividad y tino en el manejo de negocios, le encargó varias comisiones reservadas, y de gravedad, y entre otras la averiguación de origen del incendio acaecido en el Sagrario de la Catedral de México, reconocimiento de sus daños y obras necesarias para su reparo; la de otro incendio que hubo en la plaza llamada del Volador; y la averiguación y aprehensión de varios juegos de monte. A su vez, para la calificación de toda clase de vagos y formación de sus causas, y desde del 5 de noviembre de 1796 hasta junio de 1798 instruyó un total de 601 causas. ${ }^{31}$

${ }^{30}$ Albornoz, La visita de Foaquín Mosquera y Figueroa, p. 71. Sobre las causas relacionadas con Vagos, en el AGN se localiza un oficio de Joaquín Mosquera acusando de recibido la instrucción del virrey para hacerse cargo del asunto (en) AGN, Indiferente Virreinal, caja 1156, expediente 023, año 1803.

${ }^{31}$ AGN, Fondo Indiferente Virreinal, volumen 120, expediente 18, años 1795 -1799, ff. 170-178. Este expediente contiene documentos sobre el cumplimiento de la Real Orden del 24 de octubre de 1794, en la que se informa a "Su Majestad" de las circunstancias y desempeño de los ministros tribunales de América, asesores, tenientes de gobernadores y auditores de guerra. Entre ellos las relaciones de méritos de Joaquín Mosquera y Figueroa. 


\section{Segunda etapa: de México a Caracas}

Durante nueve años Joaquín Mosquera y Figueroa vivió en México. Su gestión concluyó en 1804, cuando el virrey de la Nueva España le pidió ocupar un cargo temporal en la capitanía general de Venezuela. La decisión se originó en 1803, cuando el fiscal de la Real Audiencia de Caracas, José Gutiérrez de Rivero, denunció el mal funcionamiento del tribunal y la incapacidad de los oidores y del regente, particularmente, del oidor José Bernardo de Asteguieta, por estar comprometido en actos de corrupción denunciados por el citado fiscal. Las disputas entre ambos y los enfrentamientos del fiscal con los otros ministros condujeron al decreto de una visita. Fue por eso que, el 20 de mayo de $1804,{ }^{32}$ el Consejo de Indias comisionó al virrey de la Nueva España para seleccionar un candidato que fungiera como juez encargado de esa tarea.

El virrey de la Nueva España, José de Iturrigaray, con base en la "Real Orden del nombramiento del Visitador a la Real Audiencia de Caracas, firmado en Aranjuez el 20 de mayo de 1804" comisionó temporalmente a Joaquín Mosquera y Figueroa, en ese momento oidor de la Real Audiencia de México en funciones. Por su parte, Mosquera escribió al ministro de gracia y justicia para aceptar la responsabilidad asignada y expuso que por tratarse de un cargo temporal haría el viaje sin su esposa y tres hijas. Esta decisión fue interesante en lo que respecta a su vida privada porque, a partir de esa fecha, dejó de ver a su esposa; se reencontraron en 1809, en Venezuela, cuando él zarpó hacia España, mientras ella se quedó

${ }^{32}$ Esta carta del ministro del Despacho Universal de Indias al virrey de la Nueva España para participarle de la real orden de nombramiento del visitador a la Real Audiencia de Caracas, firmada en Aranjuez el 20 de mayo de 1804, está en el Archivo General de Indias, Ramo Caracas, número 166 y fue citada en Bohorquez, La Real Audiencia de Caracas: razones de su creación, p. 43. 
resolviendo diligencias en Caracas, Colombia y México. Fue hasta 1814, en Madrid, que volvieron a reunirse. A sus hijas ya no volvió a verlas porque al ingresar al convento, no pudieron viajar a España. ${ }^{33}$

El 4 de febrero de 1805 Joaquín Mosquera y Figueroa llegó al Puerto de la Guaira de la Capitanía General de Venezuela, en calidad de regente visitador de la Real Audiencia de Caracas. "Se le dio por encargo especial, estudiar los motivos de las constantes desavenencias entre el Capitán General y la Audiencia". ${ }^{35}$

De acuerdo con el escritor Guillermo Morón, en Venezuela algunas instituciones coloniales como la Real Audiencia o la Intendencia del Ejército y la Real Hacienda, los cabildos, los municipios y las provincias, fueron importantes para consolidar poderes locales menos dependientes del virreinato de la Nueva Granada. Por ejemplo, con la ley del poder municipal fue común que las provincias de Coro, Caraballeda, Guicas, Carora, el Tocuyo, Barquisimeto, Nirgua, Valencia y Caracas funcionaran "por su cuenta y riesgo, sin gobernador, sin presidente, sin autoridad política, salvo la de sus Cabildos". ${ }^{36}$ Este hecho ayuda a entender la lejanía que mantuvo Venezuela con el gobierno de la Nueva Granada y con la monarquía española, y explica parte de la decisión tardía de crear la Capitanía General de Venezuela apenas en 1777, en el marco de las reformas borbónicas. Dichos antecedentes permiten comprender buena parte de lo que en 1804 era Venezuela y sus provincias, al igual que ayudan a dilucidar por qué ese año la monarquía decidió asignar a la Real Audiencia de Caracas facultades extraordinarias que permitieron al

${ }^{33}$ Bentura, El hidalgo payanés, pp. 200-220.

${ }^{34}$ Una síntesis sobre el origen de la Real Audiencia en Caracas se explica en Bohorquez, "La Real Audiencia de Caracas (1786-1821)", pp. 601-603. También, Teresa Albornoz, en su libro detalla los antecedentes de la Real Audiencia y la llegada de Joaquín Mosquera a Caracas con base en documentos del Archivo de Indias de Sevilla.

${ }^{35}$ Bohorquez, La Real Audiencia de Caracas: razones de su creación, p. 43.

${ }^{36}$ Morón, Guillermo, "La Real Audiencia de Caracas", p. 581. 
regente visitador tener una injerencia directa en la supervisión del ejercicio del poder político y el uso correcto de los recursos públicos.

En el siguiente testimonio es interesante la narración de Mosquera al narrar su rutina de trabajo en Caracas, que lo muestra como el observador externo y juez celoso de su deber que era en cumplimiento de su misión, prácticamente secreta, que según se lee a continuación, perseguía como objetivos reales detectar malos manejos, sobornos y actos de corrupción:

Me he ocupado, del mismo modo, de la visita del Juzgado General de Bienes de Difuntos, que estoy ya al concluir y en que he encontrado omisiones y otros defectos, de que instruiré a Vuestra Excelencia en tiempo más oportuno, habiéndoseme hecho harto reparable que no se haya colocado en las casas de la Audiencia de este juzgado, como lo está en otras partes, despachando el Juez en su casa y manteniendo el escribano en la suya, los papeles de que en mi modo de pensar han dimanado en parte la poca aplicación con que se ha procedido en el despacho de sus causas, por lo que me parecía que si fuere del soberano agrado de su Majestad se pusiese dicho juzgado y escribanía en las mismas casas de la Audiencia, en donde pueden colocarse, aunque no con toda la comodidad que sería correspondiente por ser estrechas.

Así me ha sido necesario ir alternando con las obligaciones de visitador y con las que me están anexas como a regente del mismo Tribunal, sin embargo de que las que me corresponden por este respecto me ocupan todo lo útil del día, pues acabada la diaria asistencia, que dura hasta las once, de esta hora en adelante tengo que ocuparme también en los acuerdos de los lunes y jueves: que concurrir a las Juntas Superiores de Real Hacienda los martes y sábados, y en los miércoles y viernes a las de Consolidación de Vales, que ya han quedado reducidas, a lo menos por ahora, sólo a los miércoles, de modo que 
para poder ir haciendo lo que hasta aquí va ejecutado, me he visto y veo precisado a trabajar sin reserva, en las horas del descanso, no habiéndome sido posible dejar de asistir a la Audiencia a lo menos algunos días para haber adelantado más en la Visita, por la escasez de ministros, pues ha estado casi todo el año indispuesto el Oidor don Miguel Aurioles, y solo han quedado para el despacho don José Bernardo de Asteguieta y don Felipe Martínez y varias circunstancias me han obligado a no faltar mientras no sea precisamente necesario, como me parece lo será al tiempo de la visita secreta $[s i c]$ que procuraré ir evaluando con la posible brevedad, y de modo que en lo que quepa y penda de mi arbitrio, haga menos falta en el Tribunal, y no se entienda con facilidad los testigos que se fueron examinando en ella, para asegurar más el secreto, como se encarga en semejantes actuaciones. Todo lo cual me ha parecido hacer presente a Vuestra Excelencia para que siendo de su superior agrado, se sirva trasladarlo a la soberana noticia de su Majestad. ${ }^{37}$

Por otra parte, en un expediente del AGN fechado en 1806, se leen las cartas que Mosquera envió al virrey de la Nueva España entre junio y diciembre, para informarle sobre sus actividades y expresarle la angustia que sentía porque su comisión estaba tomando más tiempo del esperado y su principal problema era estar lejos de su familia. ${ }^{38}$

${ }^{37}$ Ésta es una carta que Mosquera envió a José Antonio Caballero, firmada en Caracas, el 9 de noviembre de 1805. La original está en el Archivo General de Indias, Fondo Caracas, núm. legajo 166 y su transcripción se publicó en el apéndice documental del libro de Albornoz, La visita de Foaquín Mosquera y Figueroa, pp. 144-147.

${ }^{38}$ AGN, Fondo Indiferente Virreinal, caja 0588, "expediente Mosquera", núm. 005, 1806, 18 ff. La versión digitalizada de este expediente está publicada en www.agn.gob.mx/guiageneral (35 imágenes). Por otra parte el contenido de dichas cartas se puede analizar en Tortolero, "Un expediente en el Indiferente Virreinal", pp. 159-198. 
Estos papeles muestran varios aspectos que son interesantes de analizar. En primer lugar, llama la atención la cercana relación que Mosquera tuvo y buscó tener con los virreyes, por lo menos en Nueva Granada y Nueva España. Aquí se aprecia que durante el cargo temporal de Mosquera en Caracas, siguió en comunicación con el virrey de la Nueva España para informarle los pormenores de su visita. ${ }^{39}$

En segundo lugar, el papel de Joaquín Mosquera como funcionario dedicado a velar por los intereses de la corona española, en este caso, ante las posibles incursiones insurgentes en el Caribe y frente a los brotes en territorio venezolano, es una característica propia de su actuación en términos de la fiscalización y detección de infidentes en las colonias, especialmente porque también le fue encomendado investigar los conatos de revolución que entre 1808 y 1809 agitaron a Caracas, información que registró en sus informes oficiales. ${ }^{40}$

\section{Tercera etapa: de Caracas a Madrid}

Joaquín Mosquera y Figueroa dejó Venezuela en julio de 1809 para trasladarse a España. ${ }^{41}$ Entre sus bienes llevó un voluminoso expediente de su visita en Caracas. ${ }^{42} \mathrm{Su}$ partida sucedió al ser electo diputado para representar a Venezuela ante la Junta Suprema Central y Gubernativa del Reino de España e Indias. ${ }^{43}$

${ }^{39}$ AGN, Fondo Indiferente Virreinal, caja 841, Correspondencia de Virreyes, expediente 7, 1806, 3 ff.

${ }^{40}$ Bohorquez, La Real Audiencia de Caracas: razones de su creación, p. 43.

${ }^{41}$ Esta etapa de su vida la narra con precisión el autor Ángel Rafael Almarza Villalobos en, "Representación en la Provincia de Venezuela", pp. 11-39.

${ }^{42}$ Bohorquez, "La Real Audiencia de Caracas en la historiografía venezolana", p. 143.

${ }^{43}$ Lange, La representación venezolana en las Cortes de Cádiz, p. 223. En esta parte de su artículo la autora explica que la junta y sus planes revolucionarios fueron opuestos a los del Consejo Supremo de España e Indias. 
Las reglas para elegir diputados en los virreinatos y capitanías generales de Indias, se establecieron en la Real Orden del 22 de enero de 1809:

Se ha servido su Majestad declarar teniendo presente la consulta del Consejo de Indias de veinte y uno de noviembre último de 1808, que los reynos, provincias e islas que forman los referidos dominios deben tener representación nacional inmediata a su Real Persona y constituir parte de la Junta Central Gubernativa del Reino por medio de sus correspondientes diputados. Para que tenga efecto esta Real Resolución han de nombrar los Virreinatos de la Nueva España, el Perú, Nuevo Reino de Granada y Buenos Aires, las Capitanías Generales independientes de la isla de Cuba, Puerto Rico, Guatemala, Chile, Provincias de Venezuela y Filipinas, un individuo cada cual que represente su respectivo distrito. ${ }^{44}$

En Venezuela, el nombramiento se dio mediante un mecanismo de selección de candidatos, primero en los distintos ayuntamientos y después en el gobierno de la Capitanía General. Mosquera y Figueroa comenzó el proceso cuando fue designado candidato en la provincia de Barinas y como resultado de las votaciones generales del 20 de junio fue electo diputado. ${ }^{45}$

${ }^{44}$ Traslado de la Real Orden del 22 de enero de 1809, dirigida al presidente gobernador y capitán general de Caracas el 27 de junio de 1809, ubicada en el expediente sobre asignación de 6,000 pesos fuertes anuales de sueldo al Sr. Don Joachin [sic] Mosquera y Figueroa por ser Ministro vocal de la Junta Suprema Central de Gobierno de España e Indias y 3,000 pesos para gastos de su viaje por mar y tierra, en el Archivo General de la República Bolivariana de Venezuela (AGV), Fondo Real Audiencia, 1809, expediente 86. ${ }^{45}$ Esta fase de su designación como diputado la detallé con mayor amplitud en el artículo Tortolero, Cervantes, Yolia, "Apuntes biográficos sobre Joaquín Mosquera y Figueroa”, p. 213. 
En cuanto se enteró del resultado de las elecciones, en poco menos de mes y medio apresuró el viaje a Cádiz, incluso, en apego a la Real Orden antes citada tramitó sus viáticos de prisa, para llegar a ese puerto el 12 de agosto de 1809. Mientras tanto, en Venezuela siguieron las discusiones en torno a la validez de su candidatura, la cual fue impugnada por varios regidores del Cabildo de Caracas, quienes consiguieron anular el nombramiento mediante una resolución oficial emitida en el mes de octubre de ese mismo año cuando Mosquera ya estaba en España. ${ }^{46}$

En ese momento Mosquera y Figueroa tenía 62 años y para fortuna de su destino político le quedaban veinte años más de vida. Su futura longevidad no sería obstáculo para la continuación de su carrera política y jurídica; tampoco lo sería el cambio de continente. Cuando salió de Caracas, la Real Hacienda le aprobó a Mosquera un total de 3,000 pesos fuertes para su viaje por mar y tierra, así como los 6,000 pesos fuertes del salario que ganaría anualmente por su nuevo cargo como diputado. ${ }^{47}$ Pero al llegar a Cádiz y recibir la Real Orden sobre la nulidad de su representación, envió al Rey de España una extensa explicación para defender su nombramiento:

arrostrando por todo se declara por nula la elección hecha en el exponente sólo por no ser natural de aquellas provincias; circunstancia que no se había prevenido antes ni le había ocurrido ni podido ocurrir a nadie en la América y así se ha visto en los papeles públicos de aquellos dominios que tiene presentados al Ministerio de Gracia y Justicia, elecciones hechas para

46 Para ampliar este asunto se recomienda consultar el documento "Representación de Joaquín Mosquera y Figueroa a Su Majestad. Cádiz, 31 de octubre de 1809", consultado y transcrito por Teresa Albornoz en el Archivo General de Indias, expediente Caracas, legajo 177 (en) Albornoz, "La visita de Joaquín Mosquera y Figueroa", pp. 251-270.

${ }^{47}$ AGV, Fondo Real Audiencia, 1809, expediente 86. 
iguales diputaciones, en obispos, capitanes generales y otros empleados y personas particulares, que no sólo carecían de la inventada circunstancia de ser naturales de los reinos y provincias que habían de representar, sino que $n i$ aun eran americanos. ${ }^{48}$

Su candidatura se anuló, en medio de la corta duración de los planes de la Junta Suprema Central y Gubernativa para reunir a los diputados de Indias en España. En realidad, fue natural la...

tardanza de las comunicaciones, la (estrechez de tiempo), como lo señala el último decreto de la Junta y no permitió que se llevaran a cabo en todos los lugares la designación de los representantes locales; de ahí el hecho de que varias provincias de América no estuviesen representadas, a no ser que la Junta Electoral formada con este fin haya logrado elegir a unos residentes en España, y que no pocos diputados electos en las capitales cabezas de partidos no alcanzaron a ocupar su escaño a su debido tiempo. ${ }^{49}$

A pesar de la anulación de su designación como diputado, a los pocos meses Joaquín Mosquera obtuvo otros nombramientos: a partir de febrero de 1810 fue Ministro Togado del Consejo de Indias; en enero de 1812 fue nombrado presidente de la regencia del Reino de España, cargo que mantuvo cuando se firmó la Constitución de Cádiz en 1812 y hasta el mes de marzo de 1813; más tarde, una vez restablecido el absolutismo en España, en 1814, Mosquera hizo parte de la:

${ }^{48}$ Documento "Representación de Joaquín Mosquera y Figueroa a Su Majestad". Cádiz, 31 de octubre de 1809 (en) Albornoz, La visita de Joaquín Mosquera y Figueroa...", pp. 251-270. pp. 251-270.

${ }^{49}$ Lange, La representación venezolana en las Cortes, p. 224. 
"Comisión de causas del Estado", establecida por Fernando VII para procesar a quienes habían ocupado altos cargos durante el régimen liberal establecido por las Cortes. Finalmente, durante el Trienio Liberal fue desterrado a Valencia, pero una vez restablecido el régimen fernandino volvió a Madrid, donde murió el 25 de mayo de $1830 .{ }^{50}$

\section{Conclusión}

Los nuevos datos biográficos sobre Joaquín Mosquera y Figueroa que localizamos en documentos del AGN, permiten comprender mejor ciertos mecanismos de movilidad y ascenso profesional en el área de justicia dentro de las posesiones españolas en América.

Joaquín Mosquera y Figueroa dejó de ser oidor de la Real Audiencia de Santa Fe de Bogotá para ocupar el cargo de alcalde del crimen en la audiencia de México, un nivel administrativo de menor rango que el de oidor, no obstante que esta designación fue en realidad una forma de reconocer su experiencia y buen desempeño, en particular, por tratarse de un cargo de mayor responsabilidad institucional, sobre todo ante la complejidad que representaban los asuntos del principal tribunal de la Nueva España. Tomando esto en cuenta, Mosquera fue literalmente promovido a ocupar después el cargo de oidor. Posteriormente, se le pidió asumir un cargo temporal en la Real Audiencia de Caracas, el cual no representaba un rango mayor, sino que se trataba de una comisión delicada que podía asumir debido al dominio de su materia, a su capacidad profesional y de adaptación, pero también debido a la lealtad que mostró hacia la Corona española, en este caso, para resolver problemas relacionados con temas de corrupción y de manejo indebido de los recursos públicos.

${ }^{50}$ Expediente de Joaquín Mosquera y Figueroa "Parecer de Joaquín Mosquera y Figueroa sobre la diputación supletoria de individuos de América y Asia para las Cortes generales y extraordinarias", 7 de septiembre de 1808 (en) Bentura, "El hidalgo payanés", pp. 202-205. 
El desempeño de Joaquín Mosquera y Figueroa también aclara cómo operaron ciertos mecanismos de reconocimiento a los funcionarios americanos que prestaron servicios a la monarquía. En su caso, resulta particularmente notorio que gran parte de sus méritos se registraron en diversas pruebas documentales que hablan del desempeño de sus tareas. Éstas, en particular, ayudan a confirmar que fue un abogado disciplinado, congruente, recto, con amplio conocimiento sobre el marco legal en la burocracia y en las instituciones coloniales, además de su intensa capacidad de trabajo, cualidades que le hicieron ser alabado en reiteradas ocasiones por los virreyes de la Nueva Granada y de la Nueva España. 


\section{Referencias}

Albornoz de López, Teresa, "La visita de Joaquín Mosquera y Figueroa a la Real Audiencia de Caracas (1804-1809): conflictos internos y corrupción en la administración de justicia”, en Fuentes para la Historia Colonial en Venezuela, Caracas, Biblioteca de la Academia Nacional de la Historia, núm. 195, 1987.

Almarza Villalobos, Ángel Rafael, "Representación en la Provincia de Venezuela. Elecciones para la Junta Suprema Central y Gubernativa del Reino en 1809", en Anuario de Estudios Bolivarianos, Caracas, Universidad Simón Bolívar, año XIII, núm. 14, 2007.

Bentura, Benjamín, El hidalgo payanés don Joaquín de Mosquera y Figueroa, Madrid, Cultura Hispánica, 1971.

Bohorquez López, Alí Enrique, "La Real Audiencia de Caracas (1786-1821)", en Boletín de la Academia Nacional de la Historia, Caracas (julio-septiembre), núm. 275, 1986.

(materiales para su estudio), Caracas, Academia Nacional de la Historia. Fuentes para la historia colonial de Venezuela, 1986.

, La Real Audiencia de Caracas: razones de su creación y ejemplo de reorganización judicial borbónica, Venezuela, Academia Nacional de la Historia, 1986.

Lange, Fredérique, "La representación venezolana en las Cortes de Cádiz: José Domingo Rus", en Boletín Americanista, Barcelona, núm. 45, año xxxv, 1995.

Morón, Guillermo, "La Real Audiencia de Caracas: unidad política de Venezuela", en Boletín de la Academia Nacional de la Historia, Caracas, julio-septiembre, tomo LXIX, núm. 275, 1986. 
Rojas Salazar, Carlos Arnulfo, "Un realista neogranadino: don Joaquín Mosquera y Figueroa", en Revista de Historia y Educación Latinoamericana, Colombia, vol. 16, núm. 23, julio-diciembre de 2014.

Tortolero Cervantes, Yolia, "Un expediente en el Indiferente Virreinal del AGN: Joaquín Mosquera y el General Francisco de Miranda en la mente del Virrey José de Iturrigaray", en Legajos. Boletín del Archivo General de la Nación, México, núm. 14, 2012.

, “Apuntes biográficos sobre Joaquín Mosquera y Figueroa durante su comisión temporal como visitador y regente interino de la Real Audiencia de Caracas", en Anuario de Estudios Bolivarianos, Caracas, Instituto de Investigaciones Históricas (Bolivarium), Universidad Simón Bolívar, año XVIII, 2012-2013, núm. 19. 